\title{
Vaccine Hesitancy and Support for Employer Vaccine Mandates
}

\author{
Douglas Ashwell ${ }^{1}$, Joanna Cullinane ${ }^{2}$ and Stephen M Croucher $^{3,4 *}$ \\ ${ }^{1}$ School of Communication, Journalism and Marketing, Massey University, Palmerston North, New Zealand, ${ }^{2}$ Massey Business \\ School, Massey University, Palmerston North, New Zealand, ${ }^{3}$ School of Communication, Journalism and Marketing, Massey \\ University, Wellington, New Zealand, ${ }^{4}$ Lead Research Fellow, Higher School of Economics, National Research University, \\ Moscow, Russia
}

OPEN ACCESS

Edited by:

Leah M. Omilion-Hodges, Western Michigan University, United States

Reviewed by: Ravindra Kumar Vemula, English and Foreign Languages University, India

Isaac Nahon-Serfaty, University of Ottawa, Canada

*Correspondence:

Stephen M Croucher

s.croucher@massey.ac.nz

Specialty section: This article was submitted to Health Communication, a section of the journal Frontiers in Communication

Received: 21 September 2021 Accepted: 10 November 2021 Published: 01 December 2021

Citation:

Ashwell $D$, Cullinane $J$ and Croucher SM (2021) Vaccine Hesitancy and Support for Employer Vaccine Mandates.

Front. Commun. 6:780415. doi: $10.3389 /$ fcomm.2021.780415
This study investigated COVID-19 vaccine hesitancy and support for employer vaccine mandates and support for termination for non-vaccinated employees among a national sample in New Zealand. A total of 1852 individuals participated in the study. Results indicated participants who are able to get vaccinated are less likely to support employer mandated vaccinations and the rights of employers to terminate employees who refuse to get vaccinated. However, individuals who self-identify that they can get vaccinated and have higher confidence in the COVID-19 vaccine are more likely to get vaccinated. Age and confidence in the vaccine influence support for mandates, while age and political affiliation influenced support for employer right to terminate a non-vaccinated employee. Understanding support, or lack thereof, for such initiatives is essential as businesses and nations respond to growing COVID concerns.

Keywords: vaccine hesitancy, COVID-19, employer mandates, multiple regression, New Zealand

\section{INTRODUCTION}

\section{Vaccine Hesitancy and Support for Employer Vaccine Mandates}

The COVID-19 pandemic has resulted in large scale efforts and resources targeted to develop vaccines and to combat the disease. Previously the fastest developed vaccine was for mumps and it took 4 years (Ball, 2020). The speed of COVID-19 vaccine development was due to several factors including previous experience, rapid manufacturing, immense funding, multiple trials being conducted in parallel, and regulators moving swiftly (Ball, 2020). While these elements meant COVID-19 vaccines were developed safely and following medical protocols, a significant minority of people believe these vaccines are not safe as they were rapidly developed.

\section{Concerns About how Fast Vaccines are Developed is not New}

A review of European vaccination studies found the speed of development was a reason for people not receiving an annual influenza vaccine, vaccines against $\mathrm{H} 5 \mathrm{~N} 1, \mathrm{AH} 1 \mathrm{~N} 1$, and/or HPV vaccines (Karafillakis and Larson, 2017). In terms of the annual influenza vaccine, respondents believed the disease was mild and therefore the risk of taking a "speedily made" vaccine outweighed the risks of contracting the disease. Speed of production of pandemic influenza vaccines led some respondents to believe they may have been inadequately tested, and that this might result in the vaccines causing dangerous adverse reactions. Some concerns about the risks of HPV vaccines were also attributed to rapid development (Karafillakis and Larson, 2017). 
Other risks attributed by respondents to vaccines included beliefs that vaccines might cause the diseases they were designed to prevent (Karafillakis and Larson, 2017). Some parents thought the diseases vaccines were designed to prevent were just "childhood illnesses" and therefore not that serious. While other studies in the review reported some parents believed their children's immune systems are potentially compromised by vaccines. Another study by Lehmann et al. (2014) has found some parents believed vaccines weakened their child's immune systems. Finally, in some of the studies reviewed by Karafillakis and Larson. (2017), respondents questioned the risk of having a vaccine for diseases no longer prevalent. This highlights a modern reality that vaccinations are often the victim of their own success (Larson et al., 2011). While these perceived risks usually have no foundation in fact, they nonetheless present serious barriers for countries to reach vaccination targets to achieve herd immunity. This is an especially serious issue in the current pandemic. Not all of the perceived risks noted above are directly relevant to COVID-19. However, belief that the speed of vaccine development means vaccine safety has been compromised, mistaken belief that vaccines might cause recipients to develop COVID-19, or that vaccines cause people's immune systems to be weakened or compromised, are relevant.

New Zealand's success in keeping COVID-19 out of the country means many have not had first-hand experience with the virus. This lack of understanding combined with the perceived risks outlined above could result in a group of people who believe the risks of having a COVID-19 vaccine outweigh the benefits it may bring to them personally. Therefore, this group is unlikely to agree to any kind of government or employer mandates on a COVID-19 vaccination. This danger was highlighted in the midst of New Zealand's most recent nationwide lockdown, starting in August 2021, as the nation grappled with its first community cases of the Delta-variant of COVID-19. During the lockdown, and as the New Zealand government continued to work on an elimination strategy for COVID-19 (Ministry of Health, 2021), calls for businesses to mandate vaccines for employees returning to work after the lockdown increased and became increasingly political (Anthony, 2021; Crampton, 2021; Palmer, 2021). In fact, in October, the Government announced vaccinations would be required for all employees working in a workplace that required a certificate of vaccination for entry (Vaccination to be mandated for workplaces requiring certificates for entry, 2021). The announcement received a mixed-response from politicians, business leaders, legal experts, and the public. Such debates and associated public perceptions and reactions on the matter of mandated vaccinations, both in New Zealand and globally, give insight into the next phase of the pandemic response and will impact vaccine hesitancy behaviours and narratives.

This study applies the Health Belief Model (HBM) (Rosenstock, 1974; Carpenter, 2010), which states messages achieve optimal behavioral change if they successfully target perceived benefits, barriers, threat, and self-efficacy. There are four key parts to the HBM. First, people are more likely to take health actions (like vaccinations) if they believe they are susceptible to a negative health outcome (Rosenstock, 1966). Second, the stronger an individual's belief in the perception of the severity of the negative health outcome, the more likely they are to act to avoid that outcome. Third, individuals must believe the prescribed behaviour (vaccination) will provide positive benefits. Fourth, if individuals believe there are barriers to adopting the prescribed behavior, they will be less likely to adopt the behavior. Research has empirically supported the notion that health campaigns have a positive effect on adoption of behaviors (Hyman et al., 1994; Champion et al., 2005; Carpenter, 2010; Jones et al., 2015; Chen and Liu, 2021; Lachlan et al., 2021). Wong et al. (2020), in a Malaysian context examined health beliefs to predict intent to receive the COVID-19 vaccine. Their research showed that health beliefs, particularly susceptibility significantly affected intent to vaccinate. The authors recommended an examination of the link between vaccine hesitancy, health beliefs, and support for vaccine initiatives. The current study explores these relationships. Specifically, this study examines the extent to which vaccine hesitancy predicts support for employer mandated vaccination policies in New Zealand. Vaccine hesitancy represent health beliefs as it captures likelihood of action, belief in perception of severity, belief in positive benefits, and belief in barriers (Wong et al., 2020).

\section{VACCINE HESITANCY}

The WHO estimated under-vaccination of the world's population contributes to 2.5 million deaths annually (Shapiro et al., 2018). Under vaccinating due to vaccine fear and/or hesitancy is a critical global health threat (Shapiro et al., 2018). Vaccine hesitancy is defined as:

Delay in acceptance or refusal of vaccination despite availability of vaccination services. Vaccine hesitancy is complex and context specific, varying across time, place and vaccines. It is influenced by factors such as complacency, convenience and confidence. (Macdonald, 2015, p. 4163).

There are numerous reasons for individuals to refuse vaccines and be hesitant: religious, philosophical, alternativeviews on science, lack of consideration of consequences, and concern about the safety of vaccines. Vaccine hesitancy is often underpinned by a libertarian philosophical belief that individuals must have control over their own decision making and "truth" (Kate et al., 2021). Additionally, many individuals who are vaccine hesitant have alternative views (non-scientifically attested) on how viruses and the immune system work. There are some individuals for example who believe it is essential to acquire natural immunity and are more likely to be hesitant, reluctant, or reject vaccinations (Kate et al., 2021). Individuals who hold such alternative health beliefs may hold a "lay theory of immunity" where vaccinations are counter to their approach to health and "the immune system is viewed as central to the body's overall health, but ... it must be maintained so that it can flexibly and effectively cope with a multitude of challenges from the environment" (Casiday, 2007, p. 1062). Ma and Ma (online first) also found those who have more consideration of future and immediate consequences are more likely to vaccinate against COVID-19. 
In addition, many individuals are hesitant and reject vaccinations due to fear over the safety of vaccines (Woko et al., 2020). There are numerous historical cases of flaws in development (Currer incident of 1955), adverse reactions (swine flu vaccine in 1976), and/or misinformation (Wakefield's Lancet piece and the hepatitis B vaccine in France in 1998) that have multiplied safety fears over vaccines (CDC, 2021; Han, et al., 2019). In such cases, particularly when vaccines have been produced quickly and/or when misinformation has been spread, the reactions have been widespread and swift from those hesitant of vaccines. Individuals have refused vaccines for themselves or for their children. Such incidents are rapidly disseminated via the Internet and social media. People using the Internet to obtain health information is widespread. Fox. (2014) stated $72 \%$ of United States respondents reported they sought health information on the Internet. Another study in Norway found $62 \%$ of adults used the Internet to search for health information (Yigzaw et al., 2020).

Hesitancy toward the COVID-19 vaccine has emerged as a critical concern amid growing case numbers (Dror et al., 2020; Rhodes et al., 2020; Thaker, 2021). In particular, as Delta variant case numbers increase, hesitancy poses challenges on health systems trying to combat the spread of COVID-19 (Carpenter, 2021). COVID-19 vaccine hesitant individuals typically doubt the vaccine's safety and efficacy, even with evidence increasingly confirming the safety of the vaccines. In addition, nations are pushing to vaccinate higher proportions of their populations, to fully open economies and borders. These imperatives to open borders and economies arise not just out a desire to return to normalcy and address suppressed GDPs, but also to address the increasing risks and turbulence in global supply chains. Within these initiatives, risk-managed mainly-open borders underpinned by high immunisation rates and vaccine mandates have increasingly become the preferred governmental responses globally, but countries such as New Zealand (and until recently Australia) who have persisted in an elimination or control strategy are being criticised and labelled as having "fortress" mentalities.

Cooper and Voronov. (2021) asserted company mandates, such as those mandating COVID-19 vaccines for workers, have a legal and symbolic function. If a company mandates all employees must be vaccinated against COVID-19, that company normalizes the vaccine and symbolically says the vaccine is effective, safe, and acceptable. Over time, as more companies require employees have the vaccine, the vaccine becomes normalized and the default choice for employees, customers, and companies. In the United States, numerous companies from Delta Airlines, Facebook, Ford, Google, McDonalds, Netflix, and Walgreens have all stated they will be requiring either all staff, or all customer facing staff, to be vaccinated (Messenger, 2021). In a study conducted in September 2020, Largent et al. (2020) found that $47.7 \%$ of United States respondents believed employer-enforced employee mandates to be vaccinated were acceptable. In the United Kingdom, many firms are grappling with policies that might require new and/or existing staff to be vaccinated, while such policies are being legally scrutinised (Pickard and Cameron-
Chileshe, 2021). In various nations, health care workers have been mandated to be vaccinated: France, Greece, Italy, and Hungary. Some countries have mandated vaccination for public sector employees, and some for workers in border roles or the aged care sector. Countries such as Micronesia, Indonesia, Tajikistan, Turkmenistan, and Vatican City have mandated vaccinations for all adults (Reuters, 2021b; Reuters, 2021; Statista, 2021).

In New Zealand law, particularly the Bill of Rights Act 1990, there is a guarantee of the right of citizens to refuse medical treatment and therefore to refuse vaccinations. But New Zealand health and safety law also places obligations on managers and organisations to evaluate risk and to protect workers and customers from harm. Balancing these obligations and rights, New Zealand has the currently understood legal position that businesses cannot require any individual to be vaccinated. However, businesses can require certain front-line work roles (with higher risks) must only be done by vaccinated workers. Additionally, where there may be high risks of contracting and transmitting COVID-19 to others, businesses may also determine second line roles supporting front-line roles to also only be done by vaccinated people. So, while the government states businesses cannot generally require all employees to be vaccinated, businesses can require roles involving specific kinds of work only be done by vaccinated individuals.

Additionally, New Zealand law gives the Minister of Health and the Director General of Health the authority to make formal orders requiring workers in specific sectors to be tested or vaccinated. For example, orders to be vaccinated have been applied to border workers, managed isolation and quarantine facility workers and the education and early childcare, health and disability care and aged care sectors. This has proved important in defining the legal boundaries of vaccination mandates associated with employment as nine staff who worked for Customs on fixed term employment agreements had their contracts terminated because they were unvaccinated after April 30, 2021. One of the workers argued this constituted an unjustified dismissal and unfair disadvantage because the Bill of Rights Act 1990 means they cannot be compelled to be vaccinated. In a recent decision by the Employment Relations Authority (ERA) on this case, the claims on the dismissal and disadvantage both failed, and importantly, the ERA found that failure of an individual to be vaccinated against COVID-19 causes risk to others, and therefore being unvaccinated is contrary to a worker's obligations included in the Health and Safety at Work Act 2015 (section 45) (ERA, 2021). In this sense, while current legislation in New Zealand means that vaccination can't be directly forced in New Zealand, current and future job contracts and job descriptions might be revised if a risk to the role-holder or co-workers or customers is determined to be high (and unable to be mitigated) and this will result in some workers either needing to be vaccinated or they will potentially face redeployment or legitimised termination of employment (Palmer, 2021). The New Zealand Government has indicated that as part of its future strategy to address COVID, it intends to try to amend legislation to make it easier to enforce both worker and customer vaccine mandates in some sectors, and to permit the termination of employment of workers who refuse vaccinations. 
TABLE 1 | Demographic Information, Mean, Standard Deviation, Reliability Coefficient.

\begin{tabular}{|c|c|c|c|c|}
\hline Variable & $\mathbf{n}$ & $\mathbf{M}$ & SD & $\alpha$ \\
\hline Age & 1852 & 42.41 & 16.79 & \\
\hline \multicolumn{5}{|l|}{ Can you get vaccinated? } \\
\hline Yes & $1,412(76.2 \%)$ & & & \\
\hline No & $440(23.8 \%)$ & & & \\
\hline \multicolumn{5}{|l|}{ Sex } \\
\hline Male & $830(44.8 \%)$ & & & \\
\hline Female & $1,021(55.1)$ & & & \\
\hline Other & $1(0.1 \%)$ & & & \\
\hline \multicolumn{5}{|c|}{ Do you Have Private Health Insurance } \\
\hline Yes & $632(34.1 \%)$ & & & \\
\hline No & $1,220(65.9 \%)$ & & & \\
\hline \multicolumn{5}{|l|}{ Race } \\
\hline Pākehā (White) & $926(50 \%)$ & & & \\
\hline Māori & $557(30.1 \%)$ & & & \\
\hline Pacific Islander & $224(12.1 \%)$ & & & \\
\hline Other & 145 (7.8\%) & & & \\
\hline \multicolumn{5}{|l|}{ Highest Educational Level } \\
\hline High School & 719 (38.8\%) & & & \\
\hline 2-years degree/University & $313(16.9 \%)$ & & & \\
\hline University degree & $706(38.1 \%)$ & & & \\
\hline Post Graduate Degree & $114(6.1 \%)$ & & & \\
\hline \multicolumn{5}{|l|}{ Political Affiliation } \\
\hline National & 487 (26.3\%) & & & \\
\hline Labour & 797 (43\%) & & & \\
\hline Green & 115 (6.2\%) & & & \\
\hline Māori & $37(2 \%)$ & & & \\
\hline Other & 59 (3.2\%) & & & \\
\hline No Affiliation & 357 (19.3\%) & & & \\
\hline Confidence in Vaccines & & 4.90 & 1.94 & 0.97 \\
\hline Support for Mandates & & 3.15 & 1.22 & \\
\hline Support for Termination & & 2.54 & 1.22 & \\
\hline
\end{tabular}

In the meantime, while they wait for legislation changes, a number of companies such as Air New Zealand (national air carrier), and the Auckland Airport (NZ's largest international airport) have already made, or are proposing to make, the COVID-19 vaccine compulsory for customer facing employees (Anthony, 2021). As other companies and industries mull over this option, and as its legal merits are debated, public opinion toward such moves is developing and currently unclear (RNZ, 2021). Cooper and Voronov. (2021) stated vaccine hesitant individuals are less likely to support such mandates. However, to what extent is hesitancy linked to lack of support? This question has not been empirically explored. Thus, the following question is examined:

RQ: To what extent does vaccine hesitancy predict support for employer mandated vaccination policies in New Zealand?

\section{METHODS}

A representative sample $(n=1852)$ of New Zealand adults was collected in April-May 2021. The survey was conducted via Qualtrics. Qualtrics panels are comparable to other panels in published research (Croucher et al., 2020). Participants completed the Vaccine Hesitancy Scale, demographic questions, a question asking if they were physically able to receive the vaccination (yes or no), a question asking the extent to which they agreed with employers mandating COVID-19 vaccines ( 1 = strongly disagree to $5=$ strongly agree), and a question asking the extent to which they agreed with an employer's right to terminate an employee who refused a COVID-19 vaccine $(1=$ strongly disagree to 5 = strongly agree). Table 1 presents participant demographic information. Confirmatory factor analysis (CFA) was conducted on the Vaccine Hesitancy Scale, following criteria established by $\mathrm{Hu}$ and Bentler. (1999).

\section{Vaccine Hesitancy Scale}

Luyten et al. (2019) nine Vaccine Hesitancy Scale (VHS) assessed vaccine hesitancy. The VHS is a 5-point Likert-type scale ranging from (1) strongly disagree to (5) strongly agree. The VHS has two factors: confidence and risk perception. Sample items include, "Vaccines are effective," and "I feel comfortable getting vaccinated." Reliabilities have ranged from 0.80 to 0.95 (Luyten et al., 2019). In a previous New Zealand study with this data ${ }^{1}$, the two factor-solution did not fit: $\chi^{2}(19)=684.03, p<$ $0.0001, \mathrm{CFI}=0.88, \mathrm{RMSEA}=0.15, \mathrm{GFI}=0.92$. However, a onefactor solution with confidence in vaccines was a valid solution: $\chi^{2}$ $(9)=597.62, p<0.001, \mathrm{CFI}=0.96, \mathrm{GFI}=0.95, \mathrm{SRMR}=0.05$. Therefore, a higher score on VHS indicates higher confidence in vaccines. For the purpose of interpretation, the variable "vaccine hesitancy" is labelled "vaccine confidence".

\section{RESULTS}

To answer the research question, two multiple regressions were constructed. The first multiple regression predicted the extent to which individuals agreed with employers mandating COVID-19 vaccines (Support for Mandates). The second multiple regression predicted a closely linked aspect of the mandate debate, the extent to which individuals agreed with an employer's right to terminate an employee who refused a COVID-19 vaccine (Support for Termination). The following predictor variables were entered for both regressions: Step 1) ability to get vaccinated, Step 2) age, sex, race, highest educational level, political affiliation, and does the participant have private medical insurance, Step 3) vaccine confidence, and Step 4) a cross-product term testing for an interaction between vaccine confidence and ability to get vaccinated. Previous research in the New Zealand context has shown perceptions toward vaccine hesitancy differs among those who believe they can and cannot get vaccinated (Croucher et al., 2021). Dummy variables were created for race and political affiliation, with Pākehā ${ }^{2}$ and the Labour Party serving as reference groups.

In predicting "Support for Mandates," in model 1 the ability to get vaccinated was entered $\left(R^{2}=0.26\right)$. In model 2 , age, sex, race, educational level, political affiliation, and if a participant had

${ }^{1}$ The current study is part of a larger project

${ }^{2} \mathrm{~A}$ term from Māori language to denote white settlers and which is now taken to mean non-Māori (usually white) citizens of New Zealand who have been born in New Zealand or who have lived in New Zealand for a substantial period of time (Taonui, 2019). 
TABLE 2 | Regression Model for Support for employer Mandates.

\begin{tabular}{|c|c|c|c|c|c|c|c|c|}
\hline \multirow[t]{2}{*}{ Regressor } & \multicolumn{2}{|c|}{ Model 1} & \multicolumn{2}{|c|}{ Model 2} & \multicolumn{2}{|c|}{ Model 3} & \multicolumn{2}{|c|}{ Model 4} \\
\hline & b & SE & b & SE & b & SE & b & SE \\
\hline Intercept & 0.58 & 0.10 & 0.49 & 0.17 & 0.92 & 0.15 & 1.85 & 0.22 \\
\hline Vaccine Possible & $0.51^{\star *}$ & 0.06 & $0.44^{\star \star}$ & 0.07 & -0.02 & 0.08 & $-0.25^{\star \star}$ & 0.14 \\
\hline Age & & & $0.19^{\star \star}$ & 0.01 & 0.05 & 0.01 & $0.06^{\star \star}$ & 0.01 \\
\hline Female & & & 0.03 & 0.05 & 0.01 & 0.04 & 0.01 & 0.04 \\
\hline Māori & & & $0.04^{\star}$ & 0.06 & $0.05^{\star}$ & 0.05 & 0.04 & 0.05 \\
\hline Pacific/Islander & & & -0.01 & 0.08 & 0.01 & 0.07 & 0.01 & 0.07 \\
\hline Other Race & & & 0.01 & 0.09 & 0.01 & 0.08 & -0.01 & 0.08 \\
\hline National Party & & & -0.02 & 0.06 & 0.04 & 0.05 & 0.03 & 0.05 \\
\hline Green Party & & & 0.04 & 0.11 & 0.02 & 0.09 & 0.02 & 0.09 \\
\hline Māori Party & & & $0.05^{\star}$ & 0.17 & 0.04 & 0.15 & 0.04 & 0.14 \\
\hline Other Political Party & & & -0.02 & 0.14 & -0.02 & 0.12 & -0.02 & 0.12 \\
\hline No Political Affiliation & & & 0.01 & 0.07 & -0.02 & 0.06 & -0.01 & 0.06 \\
\hline Private Insurance & & & $-0.09^{\star \star}$ & 0.05 & -0.03 & 0.05 & -0.03 & 0.05 \\
\hline Highest Educational Level & & & $0.04^{*}$ & 0.02 & 0.01 & 0.02 & 0.01 & 0.02 \\
\hline Vaccine Confidence & & & & & $0.71^{\star \star}$ & 0.02 & $0.20^{*}$ & 0.06 \\
\hline Vaccine Confidence ${ }^{*}$ accine Possible & & & & & & & $0.70^{\star \star}$ & 0.03 \\
\hline $\mathrm{F}$ & $652.04^{\star \star}$ & & $61.53^{\star \star}$ & & $134.06^{\star \star}$ & & $129.35^{\star \star}$ & \\
\hline$\Delta \mathrm{F}$ & & & $9.37^{\star \star}$ & & $750.68^{\star \star}$ & & $31.92^{\star \star}$ & \\
\hline$R^{2}$ & 0.26 & & 0.30 & & 0.50 & & 0.51 & \\
\hline $\mathrm{R}^{2}$ adj & 0.26 & & 0.30 & & 0.50 & & 0.51 & \\
\hline
\end{tabular}

private medical insurance were entered. This model was a significant improvement over model $1\left(R^{2}=0.30 ; \Delta F=9.37\right.$, $p<0.001$ ). In model 3 , vaccine confidence was entered, this model was also a significant improvement over model $1\left(R^{2}=0.50 ; \Delta F=\right.$ $750.68, p<0.001)$. In model 4 , a cross-product of the ability to get vaccinated and vaccine confidence was entered to determine the effect of vaccine confidence and ability to get vaccinated on support for mandates. This model was a significant improvement over model $3\left(R^{2}=0.51 ; \Delta F=31.92, p<0.001\right)$. Therefore model 4 was retained for final analysis. As model 4 in Table 2 shows, there are both a main, and an interaction effect. Those individuals who are able to get the vaccine are less likely to support mandates $(b=-0.25, p<0.001)$. Older individuals are more likely to support mandates $(b=0.06, p<$ $0.05)$. Confidence in the vaccine is positively related to support for mandates $(b=0.20, p<0.05)$. Regarding the interaction effect, ability to get the vaccine and higher confidence in the vaccine is significantly related to support for employer mandates $(b=0.70, p<0.001)$.

In predicting "Support for Termination," in model 1 the ability to get vaccinated was entered $\left(R^{2}=0.08\right)$. In model 2 , age, sex, race, educational level, political affiliation, and if a participant had private medical insurance were entered. This model was a significant improvement over model $1\left(R^{2}=0.11 ; \Delta F=6.05\right.$, $p<0.001)$. In model 3 , vaccine confidence was entered, this model was also a significant improvement over model $1\left(R^{2}=0.19 ; \Delta F=\right.$ $170.46, p<0.001)$. In model 4 , a cross-product of the ability to get vaccinated and vaccine confidence was entered to determine the effect of vaccine confidence and ability to get vaccinated on support for termination. This model was a significant improvement over model $3\left(R^{2}=0.19 ; \Delta F=14.85, p<0.001\right)$. Therefore model 4 was retained for final analysis. As model 4 in Table 3 shows, there are both main, and an interaction effect. Those individuals who are able to get the vaccine are less likely to agree with companies terminating employees who refuse to vaccinate $(b=-0.65, p<0.001)$. Older individuals are more likely to agree with companies terminating non-vaccinated employees $(b=0.07, p<0.001)$. Individuals who identify with a political party other than Labour, National, Māori, or Green are less likely to support such actions $(b=-0.06, p<0.05)$. In this sample, such voters were overwhelmingly ACT voters (i.e., a right-wing, classical-liberal political party). Regarding the interaction effect, ability to get the vaccine and higher confidence in the vaccine is significantly related to support for employer's being able to terminate employees for refusing to get vaccinated $(b=0.62, p<0.001)$.

\section{DISCUSSION}

Analysing the results of this study through a HBM lens shows the intrinsic link between confidence in the COVID-19 vaccine, the virus, and support for employer mandates. The initial phases of the responses to the COVID-19 pandemic have focused on vaccine development, public health measures, lockdowns, and border restrictions coupled with vaccination programmes. Currently in New Zealand all citizens 12 and over are eligible for free COVID-19 vaccines. According to the New Zealand Medicines and Medical Devices Safety Authority, only those with a history of anaphylaxis either before or after receiving a first dose of the Pfizer vaccine (currently the vaccine of choice in New Zealand) cannot be vaccinated (Salmon et al., 2021). The public debates on the need for achieving herd immunity, and the associated public health communication programmes and sociocultural explanations for vaccine hesitancy were the second phase of the response to the pandemic. Attention has shifted to the relative rights of groups with differing views on questions of mandates related to the pandemic. The current study adds to our 
TABLE 3 | Regression Model for Support for Termination of Employees.

\begin{tabular}{|c|c|c|c|c|c|c|c|c|}
\hline \multirow[t]{2}{*}{ Regressor } & \multicolumn{2}{|c|}{ Model 1} & \multicolumn{2}{|c|}{ Model 2} & \multicolumn{2}{|c|}{ Model 3} & \multicolumn{2}{|c|}{ Model 4} \\
\hline & b & SE & b & SE & b & SE & b & SE \\
\hline Intercept & 1.17 & 0.12 & 1.44 & 0.19 & 1.70 & 0.19 & 2.52 & 0.28 \\
\hline Vaccine Possible & $0.27^{\star \star}$ & 0.06 & $0.23^{\star \star}$ & 0.08 & -0.06 & 0.10 & $-0.26^{\star \star}$ & 0.18 \\
\hline Age & & & $0.14^{\star \star}$ & 0.01 & $0.06^{*}$ & 0.01 & $0.07^{\star \star}$ & 0.01 \\
\hline Female & & & -0.03 & 0.06 & -0.04 & 0.05 & -0.04 & 0.05 \\
\hline Māori & & & -0.01 & 0.06 & -0.01 & 0.06 & -0.02 & 0.06 \\
\hline Pacific/Islander & & & -0.04 & 0.09 & -0.04 & 0.09 & -0.04 & 0.09 \\
\hline Other Race & & & -0.01 & 0.11 & -0.02 & 0.10 & -0.02 & 0.10 \\
\hline National Party & & & 0.01 & 0.07 & 0.03 & 0.07 & 0.03 & 0.07 \\
\hline Green Party & & & 0.04 & 0.12 & 0.03 & 0.11 & 0.03 & 0.11 \\
\hline Māori Party & & & $0.07^{\star \star}$ & 0.20 & $0.07^{\star \star}$ & 0.19 & 0.07 & 0.19 \\
\hline Other Political Party & & & $-0.06^{\star}$ & 0.16 & $-0.06^{\star \star}$ & 0.15 & $-0.06^{\star}$ & 0.15 \\
\hline No Political Affiliation & & & -0.01 & 0.08 & -0.01 & 0.07 & -0.01 & 0.07 \\
\hline Private Insurance & & & $-0.09^{\star \star}$ & 0.06 & $-0.04^{*}$ & 0.06 & -0.04 & 0.06 \\
\hline Highest Educational Level & & & 0.01 & 0.03 & -0.02 & 0.03 & -0.01 & 0.03 \\
\hline Vaccine Confidence & & & & & $0.43^{\star \star}$ & 0.02 & -0.02 & 0.08 \\
\hline Vaccine Confidence*Vaccine Possible & & & & & & & $0.62^{\star \star}$ & 0.04 \\
\hline \multirow[t]{2}{*}{$\mathrm{F}$} & $149.12^{\star \star}$ & & & & & & & \\
\hline & & & $17.43^{\star \star}$ & & $29.86^{\star \star}$ & & $29.07^{\star \star}$ & \\
\hline \multirow[t]{2}{*}{$\Delta \mathrm{F}$} & & & $6.05^{\star \star}$ & & & & & \\
\hline & & & & & $170.46^{\star \star}$ & & $14.85^{\star \star}$ & \\
\hline$R^{2}$ & 0.08 & & 0.11 & & 0.19 & & 0.19 & \\
\hline $\mathrm{R}^{2} \mathrm{adj}$ & 0.07 & & 0.10 & & 0.18 & & 0.19 & \\
\hline Note: ${ }^{*} p<0.05,{ }^{* *} p<0.001$ & & & & & & & & \\
\hline
\end{tabular}

understanding of how the public responds to questions surrounding such proposed mandates. Individuals who selfidentify as being able to get vaccinated, are less likely to support employer mandated vaccinations and the rights of employers to terminate employees who refuse to get vaccinated. When those who believe in the risk of the virus, believe in the positive benefits of the vaccine, and know the barriers tend to have more confidence in the vaccine. However, individuals who self-identify that they can get vaccinated and have higher confidence in the vaccine are more likely to get vaccinated. We explain these results below.

\section{Vaccine Hesitancy and Non-Compliance}

For as long as there has been public vaccination programmes, there has been vaccine hesitancy (Blume, 2006). During the current pandemic, public health messaging associated with vaccinations has concentrated on three related and interlinking themes: explaining the role vaccination plays in reducing risk to an individual personally; a social group pressure response "we are all in this together" e.g., the New Zealand "Ka kite covid!" campaign; and alluding to protection and increased normalcy through herd immunity (Dubé et al., 2013; Luyten et al., 2019).

However, these messages are challenged by increasingly complex issues for vaccination non-compliance, which bely normal assumptions that hesitancy is related to an incomplete understanding of safety or benefits. For example, in regions where vaccines have been effective in reducing transmissible diseases the willingness to receive vaccines among defined groups is relatively lower even though that group understands vaccinations are effective (LaCour and Davis, 2020). This may be a form of "vaccine calculus," which arises where the risk of the disease being contracted is low because of previous or current high vaccination rates among fellow citizens, thus changing the evaluation of risk and return (Conis, 2013). Other examples of these complex non-compliance issues have included research highlighting the relationship between political affiliations and motivation to be vaccinated (although the direction of causality is unclear) (Calvillo et al., 2020).

An Australian study by Smith et al. (2021) examined vaccine hesitancy and found those who voted for Australia's two major political parties were more in favour of mandatory vaccination while those voting for minor parties were not. It is interesting to note that similarly to Smith et al. (2021) study in Australia, this current study also found that supporters of New Zealand's two major political parties, Labour and National, generally more often supported termination of un-vaccinated employees than supporters of other political parties. However, when it came to minor parties, there were mixed results with supporters of the Green and Māori parties agreeing with the termination of non-vaccinated employees, while those supporting the classical-liberal, right-wing ACT party did not. Given the classical-liberal, individualistic underpinnings of the ACT party, the latter result is not unsurprising. It is also interesting to note older respondents in Smith et al. Australian study (2021) were more likely to support mandatory vaccination and older respondents in this study were more likely to agree with the 
termination of non-vaccinated employees. The latter could be due to the fact that older people appear more susceptible to COVID-19 and also some may remember the devastating effects of polio, measles, and tuberculosis outbreaks when they were younger.

Research has also highlighted an unclear link between levels of education and vaccination. Some research has shown the most highly educated members of society express high levels of unwillingness to be vaccinated while still having high confidence in the efficacy of vaccinations (MacDonald, 2015). While Rhodes et al. (2020) found that the more highly educated parents were more likely to vaccinate themselves and their children.

The questions of social compulsion in terms of employment may be the next phase in the pandemic response, given hesitancy arises from multiple forms. For instance, if employers mandate vaccination and have the right to terminate employment where vaccination has not been undertaken, then the complex patterns of hesitancy which takes the form of informed/educated reluctance and vaccine calculus might be addressed because the potential loss of income by the individual will alter the risk and reward evaluations. Similarly, more "traditional" understandings of hesitancy arising from ignorance or social pressures may be addressed by mandating vaccination through employment and other spheres of civil society.

This research showed low support among those who selfidentify as being able to be vaccinated towards employers mandating vaccination and being able to enforce this with termination. Additionally, the modelling examined acceptability of employers mandating vaccination and being able to enforce this with termination based on the respondent's confidence in vaccination. It is evident that even if a person self-identifies themselves as able to receive the COVID-19 vaccination, their belief that employers should be able to mandate vaccination and sanction non-vaccination through termination is not strong unless they also have strong confidence in the efficacy of the vaccination.

In New Zealand, vaccination has only ever been mandatory for smallpox (between 1863 and 1920), with a brief period of non-compulsion in 1872. Since 1920, New Zealand has relied on educational campaigns and public health initiatives to combat vaccine-preventable diseases (Te Ara- The Encyclopaedia of New Zealand, 2021). Public health efforts in New Zealand have tended to concentrate on vaccinating children, pregnant women, and the elderly. Most public health initiatives arise from the work of General Practitioners and Plunket $^{3}$ who are in turn supported by government funding agreements and immunisation subsidies (Nowlan, et al., 2019). Previous research examining mandatory vaccination suggest an educational approach is the best option (Shachar and Reiss, 2020; Smith et al., 2021).

${ }^{3}$ Plunket is a not-for-profit organisation that supports expectant parents and families with new-borns over the first 1,000 days of the child's life. Plunket are estimated to currently care for $85 \%$ of families of new-borns in New Zealand. Their work is both educational and provides free health and development checks.

\section{Employer-Located Compulsion}

These results add further understanding to the part employerlocated compulsion could play in raising vaccination rates. The first major test of this matter in the ERA in September 2021 will soon start to be widely understood in the court of public opinion (ERA, 2021). That decision determined it may be justifiable to terminate the employment of unvaccinated employees even though the Bill of Rights guarantees citizens may not be forced to be vaccinated. While people will have the absolute right not to be vaccinated, this will not protect them from potentially having their employment terminated. More importantly, the ERA decision determined the personal risk to an individual of being unvaccinated is only one consideration for an employer, and the risk that an unvaccinated worker poses to other workers and customers must also be considered and can be cause for justifying termination.

This second aspect of the decision is critical as it speaks to the potential for unemployment for those who are unvaccinated. The next major legal tests for employment mandates will be how the law approaches cases entirely separate from border workers and how the law will adjust to questions of discrimination raised by both voluntarily and involuntarily unvaccinated workers. There may also be questions of protections against discrimination for those who have been vaccinated but fail to develop antibodies.

As noted, previous research has suggested education rather than mandatory vaccination and subsequent employment termination for unvaccinated individuals should be the preferred action taken by Governments and employers. Indeed Mello et al. (2020) argue that before vaccines are made mandatory the following six criteria should be met: 1) The virus is not adequately contained, 2) Authorities have recommended vaccines for population groups for which mandatory vaccination is being considered, 3) Sufficient supply of vaccines is available, 4) Evidence of the vaccine's safety and efficacy has been clearly communicated, 5) Infrastructure exists to supply vaccines without any barriers, assistance is available to workers who may suffer adverse effects of vaccines and real time surveillance of vaccine side-effects is available, and 6) Uptake of vaccines has not reached the required target within a given time period.

When these criterion are examined in terms of the New Zealand context it could be argued it is too early for New Zealand to consider mandatory vaccination and any widespread move towards employment termination for unvaccinated workers. First, New Zealand eliminated the COVID-19 virus for a considerable period of time until a recent outbreak of the Delta variant in August 2021. So the first criteria does not seem to be applicable at this time. The second criteria has been met with the Government identifying populations for mandatory vaccination. However, the third criterion of having sufficient supply of vaccine was only met in September 2021. In terms of clear communication of the vaccines efficacy and safety, this is open to debate as certain groups, especially the indigenous Māori.

Population, have suggested this has not been clearly communicated to them and these groups still face barriers 
to being vaccinated (Triponel, 2021). Therefore, the fourth and fifth criteria have not been fully met. Although real-time surveillance of vaccine side-effects does exist as does support for those who may suffer side-effects. Finally, a definitive target for vaccination has not been stated. Given these points it does appear too early to suggest mandatory vaccination and subsequent employment termination for unvaccinated workers. Rather it may be better to educate with the addition of other social moves being suggested in other countries such as a vaccine passports. The latter would allow people into cafes, bars, and concerts (Mannheim, 2021). While the ethics of such passports are under question, they may create the social pressure needed to increase vaccination to the required rates without having to resort to mandatory vaccinations or other more punitive measures. Moreover, more targeted communications about the safety and efficacy of the vaccine need to be developed to answer the fears and possible misunderstandings in particular groups, for example Māori and Pasifika ${ }^{4}$. Calls have been made by both groups that such communication needs to occur in more culturally appropriate settings. For example, Marae ${ }^{5}$ for Māori and churches for Pasifika for whom the church plays a large role in their communities. Also the communication needs to be conducted by those from the recipients own culture so the messages can be better understood and trusted. While such calls are slowly being heeded in New Zealand, the delay in tailoring such messages has cost valuable time in terms of lower vaccination rates among certain groups. Finally, some parts of the New Zealand population live in remote rural areas and this includes many Māori therefore the Government needs to insure better access to vaccination is made available in these regions before considering vaccine mandates if it is to adhere to Mello et al. (2020) guidelines.

\section{CONCLUSION AND FUTURE RESEARCH}

If/when COVID-19 becomes an endemic disease it will be important to consider the mutual views of the vaccinated/ unvaccinated towards each other. The individual beliefs people hold for, and against, vaccination to combat COVID-19 are likely to be both personal and strongly felt. Unlike many other strongly held personal decisions, individuals in the pro-vaccination group are likely to have strongly held views about the anti-vaccination group's obligations to participate in a social-contract, and they may view anti-vaccination attitudes as dangerous freeloading. However, as many citizens who hold anti-vaccination beliefs feel vaccinations are a risk to their well-being, they may view pro-vaccinations attitudes towards them as infringements on their basic human rights to safety and autonomy. These issues are not just theoretical; each side is

${ }^{4}$ People living in New Zealand who have migrated from or identify with Pacific Island because of ancestry and heritage settling into a tactical contestation. The pro-vaccination side has changed their strategy as many countrie's COVID-19 vaccination programmes risk falling below levels necessary for herd immunity. Their strategies are shifting now from ${ }^{4}$ public health communication initiatives to utilising other enticements, social nudges and mandates to "encourage" or "leverage" people to be vaccinated. However, before using such levers, the New Zealand Government should insure all possible targeted communication measures have been exhausted and that more isolated individuals have afforded equal access to vaccines. Such targeted messaging is more likely to promote action (vaccination), belief in perception of severity of the virus, belief in positive benefits of the vaccine, and increase understanding of the barriers to vaccination. If not the shift towards other initiatives may result in those people who hold anti-vaccination attitudes feeling increasing pressures to be vaccinated. In many countries like New Zealand, this vaccine hesitant group ${ }^{5}$ are still a sizeable minority of citizens, and so we will need to consider the impact their disaffection will have on society in the long-term.

Pro-vaccination views will be that any disaffection of the antivaccination minority may be a small price to pay compared to a future where COVID-19 remains an acute disease with high morbidity and mortality rates. Nevertheless there will be changes to society arising from these unresolved debates. We can expect to see shifts in people's employment prospects and we can potentially expect to see the creation of unvaccinated underclasses. For the individuals who are both unvaccinated or who are vaccinated but do not have an immune response to the vaccination, we might see accidental alliances formed as both groups will potentially face discrimination in employment and society. Finally, we may also anticipate organisations that follow mandates will see shifts in their potential employee talent pools as the unvaccinated minority fall outside their hiring preferences.

The primary limitation of this article is its cross-sectional design. As demonstrated with other research, attitudes toward the COVID-19 vaccine and vaccine hesitancy shift (Rhodes et al., 2020; Sylvia Chou and Budenz, 2020; Ma and Ma, 2021; Thaker, 2021). Thus, future research could benefit from longitudinally exploring vaccine hesitancy and confidence.

The study findings clearly document how someone's ability to get vaccinated and their confidence in the COVID-19 vaccination influences their acceptance of an employer's right to mandate the COVID-19 vaccination and to be able to terminate employees for non-compliance. While this issue is still evolving in the New Zealand context, and in other contexts, these findings highlight the importance of understanding how the public perceives such mandates. These insights could guide companies as they continue to internally mull over and weigh the options legally and in the court of public opinion. 


\section{DATA AVAILABILITY STATEMENT}

The raw data supporting the conclusions of this article will be made available by the authors, without undue reservation.

\section{ETHICS STATEMENT}

The studies involving human participants were reviewed and approved by Massey University. Written informed consent for

\section{REFERENCES}

Anthony, J. (2021). Auckland Airport Introduces Compulsory COVID-19 Vaccination Policy for Front Line Staff and New Employees. Stuff. Available at: https://www.stuff.co. nz/business/industries/126272425/auckland-airport-introduces-compulsory-covid19vaccination-policy-for-front-line-staff-and-new-employees.

Ball, P. (2020). The Lightning-Fast Quest for COVID Vaccines - and what it Means for Other Diseases. Nature 589, 16-18. doi:10.1038/d41586-020-03626-1

Blume, S. (2006). Anti-vaccination Movements and Their Interpretations. Soc. Sci. Med. 62 (3), 628-642. doi:10.1016/j.socscimed.2005.06.020

Calvillo, D. P., Ross, B. J., Garcia, R. J. B., Smelter, T. J., and Rutchick, A. M. (2020). Political Ideology Predicts Perceptions of the Threat of COVID-19 (And Susceptibility to Fake News about it). Soc. Psychol. Personal. Sci. 11 (8), 1119-1128. doi:10.1177/1948550620940539

Carpenter, C. J. (2010). A Meta-Analysis of the Effectiveness of Health Belief Model Variables in Predicting Behavior. Health Commun. 25 (8), 661-669. doi:10.1080/10410236.2010.521906

Carpenter, P. (2021). COVID-19 Vaccine Hesitance a Concern amid Rising Case Numbers. Global News.ca. Available at: https://globalnews.ca/news/8168137/ covid-19-vaccine-hesitancy/ (Online).

Casiday, R. E. (2007). Children's Health and the Social Theory of Risk: Insights from the British Measles, Mumps and Rubella (MMR) Controversy. Soc. Sci. Med. 65 (5), 1059-1070. doi:10.1016/j.socscimed.2007.04.023

CDC (2021). Vaccine Safety. Historical Vaccine Safety Concerns. Centres For Disease Control and Prevention. Available at: https://www.cdc.gov/ vaccinesafety/concerns/concerns-history.html (Online).

Champion, V., Skinner, C. S., and Menon, U. (2005). Development of a SelfEfficacy Scale for Mammography. Res. Nurs. Health 28, 329-336. doi:10.1002/ nur.20088

Chen, Y., and Liu, X. (2021). Determinants of Beijing Residents' Intentions to Take Protective Behaviors against Smog: An Application of the Health Belief Model. Health Commun., 1-13. doi:10.1080/10410236.2021.1956036

Chou, W.-Y. S., and Budenz, A. (2020). Considering Emotion in COVID-19 Vaccine Communication: Addressing Vaccine Hesitancy and Fostering Vaccine Confidence. Health Commun. 35 (14), 1718-1722. doi:10.1080/ 10410236.2020.1838096

Conis, E. (2013). A Mother's Responsibility: Women, Medicine, and the Rise of Contemporary Vaccine Skepticism in the United States. Bull. Hist. Med. 87 (3), 407-435. doi:10.1353/bhm.2013.0047

Cooper, M., and Voronov, M. (2021). Why Business Leaders Need to Mandate the COVID-19 Vaccine. Harvard Business Review. Available at: https://hbr.org/2021/09/ why-business-leaders-need-to-mandate-the-covid-19-vaccine (Online).

Crampton, E. (2021). University, Employer Vaccination Mandates Could Be Illegal - and that Is Wrong. Stuff. Available at: https://www.stuff.co.nz/business/ opinion-analysis/126289869/university-employer-vaccination-mandatescould-be-illegal-and-that-is-wrong?cid=app-android (Online).

Croucher, S., Ashwell, D., and Cullinane, J. (2021). New Zealand has Ramped up Vaccination Rates, but too many People Remain Concerned About Vaccine Safety. The Conversation. Available at: https://theconversation.com/newzealand-has-ramped-up-vaccination-rates-but-too-many-people-remainconcerned-about-vaccine-safety-167984.

Croucher, S. M., Nguyen, T., and Rahmani, D. (2020). Prejudice toward Asian Americans in the Covid-19 Pandemic: The Effects of Social Media Use in the United States. Front. Commun. 5, 39. doi:10.3389/fcomm.2020.00039 participation was not required for this study in accordance with the national legislation and the institutional requirements.

\section{AUTHOR CONTRIBUTIONS}

All authors listed have made a substantial, direct, and intellectual contribution to the work and approved it for publication.

Dror, A. A., Eisenbach, N., Taiber, S., Morozov, N. G., Mizrachi, M., Zigron, A., et al. (2020). Vaccine Hesitancy: The Next challenge in the Fight against COVID-19. Eur. J. Epidemiol. 35, 775-779. doi:10.1007/s10654-020-00671-y

Dubé, E., Laberge, C., Guay, M., Bramadat, P., Roy, R., and Bettinger, J. A. (2013). Vaccine Hesitancy. Hum. Vaccin. Immunother. 9 (8), 1763-1773. doi:10.4161/ hv. 24657

Employment Relations Authority (2021). GF V New Zealand Customs Service 01 September 2021 [2021] NZERA 382 [Employment Relations Authority Christchurch]. Available at: https://www.employment.govt.nz/assets/elawpdf/ 2021/2021-NZERA-382.pdf.

Fox, S. (2014). The Social Life of Health Information. Available at: https://www. pewresearch.org/fact-tank/2014/01/15/the-social-life-of-health-information/.

Han, B., Wang, S., Wan, Y., Liu, J., Zhao, T., Cui, J., et al. (2019). Has the Public Lost Confidence in Vaccines Because of a Vaccine Scandal in China. Vaccine 37 (36), 5270-5275. doi:10.1016/j.vaccine.2019.07.052

Hu, L. T., and Bentler, P. M. (1999). Cutoff Criteria for Fit Indexes in Covariance Structure Analysis: Conventional Criteria versus New Alternatives. Struct. Equation Model. A Multidisciplinary J. 6 (1), 1-55. doi:10.1080/ 10705519909540118

Hyman, R. B., Baker, S., Ephraim, R., Moadel, A., and Philip, J. (1994). Health Belief Model Variables as Predictors of Screening Mammography Utilization. J. Behav. Med. 17, 391-406. doi:10.1007/bf01858010

Jones, C. L., Jensen, J. D., Scherr, C. L., Brown, N. R., Christy, K., and Weaver, J. (2015). The Health Belief Model as an Explanatory Framework in Communication Research: Exploring Parallel, Serial, and Moderated Mediation. Health Commun. 30 (6), 566-576. doi:10.1080/10410236.2013.873363

Karafillakis, E., and Larson, H. J. (2017). The Benefit of the Doubt or Doubts over Benefits? A Systematic Literature Review of Perceived Risks of Vaccines in European Populations. Vaccine 35 (37), 4840-4850. doi:10.1016/j.vaccine.2017.07.061

Lachlan, K. A., Eastman, A., and Gilbert, C. (2021). Responses to Risk Messaging Concerning Hurricane Sandy: Two Studies Utilizing the Health Belief Model. Atlantic J. Commun. 29 (4), 216-229. doi:10.1080/15456870.2020.1754823

LaCour, M., and Davis, T. (2020). Vaccine Skepticism Reflects Basic Cognitive Differences in Mortality-Related Event Frequency Estimation. Vaccine 38 (21), 3790-3799. doi:10.1016/j.vaccine.2020.02.052

Largent, E. A., Persad, G., Sangenito, S., Glickman, A., Boyle, C., and Emanuel, E. J. (2020). US Public Attitudes toward COVID-19 Vaccine Mandates. JAMA Netw. Open 3, e2033324. doi:10.1001/jamanetworkopen.2020.33324

Larson, H. J., Cooper, L. Z., Eskola, J., Katz, S. L., and Ratzan, S. (2011). Addressing the Vaccine Confidence gap. The Lancet 378 (9790), 526-535. doi:10.1016/ s0140-6736(11)60678-8

Lehmann, B. A., Ruiter, R. A. C., Chapman, G., and Kok, G. (2014). The Intention to Get Vaccinated against Influenza and Actual Vaccination Uptake of Dutch Healthcare Personnel. Vaccine 32, 6986-6991. doi:10.1016/j.vaccine.2014.10.034

Luyten, J., Bruyneel, L., and van Hoek, A. J. (2019). Assessing Vaccine Hesitancy in the UK Population Using a Generalized Vaccine Hesitancy Survey Instrument. Vaccine 37 (18), 2494-2501. doi:10.1016/j.vaccine.2019.03.041

Ma, Z., and Ma, R. (2021). Predicting Intentions to Vaccinate against COVID-19 and Seasonal Flu: The Role of Consideration of Future and Immediate Consequences. Health Commun., 1-10. doi:10.1080/10410236.2021.1877913

MacDonald, N. E. (2015). Vaccine Hesitancy: Definition, Scope and Determinants. Vaccine 33 (34), 4161-4164. doi:10.1016/j.vaccine.2015.04.036

Mannheim, M. (2021). Vaccination Passports are Being Considered Around the World, but the ACT is Unlikely to Ease COVID-19 Restrictions for Double-Dosed Canberrans. ABC News. Available at: https://www.abc.net.au/ 
news/2021-09-17/act-unlikely-to-ease-covid-restrictions-for-fully-vaccinated/ 100465624.

Mello, M. M., Silverman, R. D., and Omer, S. B. (2020). Ensuring Uptake of Vaccines against SARS-CoV-2. N. Engl. J. Med. 383 (14), 1296-1299. doi:10.1056/NEJMp2020926

Messenger, H. (2021). From McDonald's to Goldman Sachs, Here Are the Companies Mandating Vaccines for All or Some Employees. NBC News. Available at: https://www.nbcnews.com/business/business-news/here-arecompanies-mandating-vaccines-all-or-some-employees-n1275808.

Ministry of Health (2021). Covid-19: Elimination Strategy for Aotearoa New Zealand. Available at: https://www.health.govt.nz/our-work/diseasesand-conditions/covid-19-novel-coronavirus/covid-19-response-planning/ covid-19-elimination-strategy-aotearoa-new-zealand.

Nowlan, M., Willing, E., and Turner, N. (2019). Influences and Policies that Affect Immunisation Coverage-A Summary Review of Literature. N. Z. Med. J. 132 (1501), 79-88.

Palmer, R. (2021). Minister Rejects Mandatory Worker Vaccines for Wider New Zealand. RNZ. Available at: https://www.rnz.co.nz/news/political/450075/ minister-rejects-mandatory-worker-vaccines-for-wider-new-zealand (Online).

Pickard, J., and Camerson-Chileshe, J. (2021). UK Ministers Back Companies that Insist Staff Must Be Fully Vaccinated. Financial Times. Available at: https:// www.ft.com/content/79f11f93-9308-46b2-8b51-938b35d316cc (Online).

Reuters (2021b). Asia Pacific. Turkmenistan Makes COVID-19 Vaccination Mandatory. Reuters. Available at: https://www.reuters.com/world/asia-pacific/ turkmenistan-makes-covid-19-vaccination-mandatory-2021-07-07/ (Online).

Reuters (2021). Factbox: Countries Making COVID-19 Vaccines Mandatory. Reuters. Available at: https://www.reuters.com/world/countries-make-covid19-vaccines-mandatory-2021-07-13/ (Online).

Rhodes, M. E., Sundstrom, B., Ritter, E., McKeever, B. W., and McKeever, R. (2020). Preparing for A COVID-19 Vaccine: A Mixed Methods Study of Vaccine Hesitant Parents. J. Health Commun. 25 (10), 831-837. doi:10.1080/10810730.2021.1871986

RNZ (2021). Vaccination to Be Mandated for Workplaces Requiring Certificates for Entry. RNZ. Available at: https://www.rnz.co.nz/news/national/454291/ watch-vaccination-to-be-mandated-for-workplaces-requiring-certificates-forentry (Online).

Rosenstock, I. M. (1974). Historical Origins of the Health Belief Model. Health Edu. Monogr. 2, 328-335. doi:10.1177/109019817400200403

Rosenstock, I. M. (1966). Why People Use Health Services. Milbank Memorial Fund Q. 44, 94-127. doi:10.2307/3348967

Salmon, P., Mortimer, N., Walker, C., Jackson, R., Empson, M., Seine, A., et al. (2021). Seven Experts' Opinion: Almost Every Eligible New Zealander Can Safely Receive Pfizer Vaccine. New Zealand Herald. Available at: https://www. nzherald.co.nz/nz/seven-experts-opinion-almost-every-eligible-new-zealandercan-safely-receive-pfizer-vaccine/EFMPFHKPKQOIG3XP4UGXCERMYE/.

Shachar, C., and Reiss, D. R. (2020). When Are Vaccine Mandates Appropriate. AMA J. Ethics 22 (1), E36-E42. doi:10.1001/amajethics.2020.36

Shapiro, G. K., Tatar, O., Dube, E., Amsel, R., Knauper, B., Naz, A., et al. (2018). The Vaccine Hesitancy Scale: Psychometric Properties and Validation. Vaccine 36 (5), 660-667. doi:10.1016/j.vaccine.2017.12.043

Smith, D. T., Attwell, K., and Evers, U. (2021). Support for a COVID-19 Vaccine Mandate in the Face of Safety Concerns and Political Affiliations:
An Australian Study. Politics, 026339572110090-12. doi:10.1177/ 02633957211009066

Statista (2021). COVID-19 Pandemic. The Countries where Vaccination is Mandatory. Statista. Available at: https://www.statista.com/chart/25326/ obligatory-vaccination-against-covid-19/ (Online).

Taonui, R. (2019). What's in a Name? How 'Pākehä' Became Corrupted the Dominion Post. Stuff. Available at: https://www.stuff.co.nz/life-style/life/ 112533002/whats-in-a-name-how-pkeh-became-corrupted (Online).

Te Ara Encyclopaedia of New Zealand (2021). Healthy Bodies-Immunisation. Available at: https://teara.govt.nz/en/public-health/page-4.

Ten Kate, J., Koster, W. D., and Van der Waal, J. (2021). "Following Your Gut" or "Questioning the Scientific Evidence": Understanding Vaccine Skepticism Among More-Educated Dutch Parents. J. Health Soc. Behav. 62 (1), 85-99. doi:10.1177/0022146520986118

Thaker, J. (2021). The Persistence of Vaccine Hesitancy: COVID-19 Vaccination Intention in New Zealand. J. Health Commun. 26 (2), 104-111. doi:10.1080/ 10810730.2021 .1899346

Triponel, T. R. (2021). COVID 19 Coronavirus: Māori and Pasifika Most Vulnerable. NZ Herald. Available at: https://www.nzherald.co.nz/kahu/covid19-coronavirus-maori-and-pasifika-most-vulnerable-but-hesitant-in-gettingvaccine/OMLFFXN555LO3VG6YIRKBHYEXA/ (Online).

Woko, C., Siegel, L., and Hornik, R. (2020). An Investigation of Low COVID-19 Vaccination Intentions Among Black Americans: The Role of Behavioral Beliefs and Trust in COVID-19 Information Sources. J. Health Commun. 25 (10), 819-826. doi:10.1080/10810730.2020.1864521

Wong, L. P., Alias, H., Wong, P.-F., Lee, H. Y., and AbuBakar, S. (2020). The Use of the Health Belief Model to Assess Predictors of Intent to Receive the COVID-19 Vaccine and Willingness to Pay. Hum. Vaccin. Immunother. 16 (9), 2204-2214. doi:10.1080/21645515.2020.1790279

Yigzaw, K. Y., Wynn, R., Marco-Ruiz, L., Budrionis, A., Oyeyemi, S. O., Fagerlund, A. J., et al. (2020). The Association between Health Information Seeking on the Internet and Physician Visits (The Seventh Tromsø Study - Part 4): Population-Based Questionnaire Study. J. Med. Internet Res. 22 (3), e13120. doi:10.2196/13120

Conflict of Interest: The authors declare that the research was conducted in the absence of any commercial or financial relationships that could be construed as a potential conflict of interest.

Publisher's Note: All claims expressed in this article are solely those of the authors and do not necessarily represent those of their affiliated organizations, or those of the publisher, the editors and the reviewers. Any product that may be evaluated in this article, or claim that may be made by its manufacturer, is not guaranteed or endorsed by the publisher.

Copyright $\odot 2021$ Ashwell, Cullinane and Croucher. This is an open-access article distributed under the terms of the Creative Commons Attribution License (CC BY). The use, distribution or reproduction in other forums is permitted, provided the original author(s) and the copyright owner(s) are credited and that the original publication in this journal is cited, in accordance with accepted academic practice. No use, distribution or reproduction is permitted which does not comply with these terms. 